\title{
Unusually high sea level at the south coast of Japan in September 2011 induced by the Kuroshio
}

\author{
Norihisa Usui ${ }^{1}$ (1) Koji Ogawa $^{3} \cdot$ Kei Sakamoto $^{1} \cdot$ Hiroyuki Tsujino $^{2} \cdot$ Goro Yamanaka $^{1} \cdot$ Tsurane Kuragano $^{4}$. \\ Masafumi Kamachi ${ }^{5}$
}

Received: 20 April 2020 / Revised: 26 October 2020 / Accepted: 27 October 2020 / Published online: 9 November 2020

(c) The Author(s) 2020

\begin{abstract}
Using a coastal assimilation model, generation mechanism of unusually high sea level (UHSL) at the south coast of Japan in September 2011 is investigated. Both model results and tide gauge observations indicate that sea level rise associated with the UHSL event occurred twice in the middle and end of September. The first one, which is localized around the eastern part of the Seto Inland Sea, is caused by a cyclonic circulation in the Kii Channel formed as a result of northward migration of the Kuroshio axis toward Cape Shionomisaki. The second sea level rise, which is the main contributor to this UHSL event, is observed in wide areas not only at the south coast of Japan, but also at the coast of the Japan Sea. It is brought about by a coastal trapped wave (CTW) induced as a result of a fluctuation of the Kuroshio path to the south of the Boso Peninsula. The CTW with positive SSH anomalies propagates westward along the south coast of Japan, and then goes into the coast of the Japan Sea. Sensitivity experiments and a modal characteristic analysis indicate that the CTW is mainly characterized by the first mode baroclinic Kelvin wave. The phase speed for the first mode is calculated at $2.96 \mathrm{~m} \mathrm{~s}^{-1}$, which compares well with that estimated by tide gauge observations.
\end{abstract}

Keywords Unusually high sea level $\cdot$ Coastal sea level $\cdot$ Coastal trapped wave $\cdot$ Kuroshio path $\cdot$ Coastal assimilation model

Norihisa Usui

nusui@mri-jma.go.jp

1 Department of Atmosphere, Ocean, and Earth System Modeling Research, Meteorological Research Institute, 1-1 Nagamine, Tsukuba, Ibaraki 305-0052, Japan

2 Department of Climate and Geochemistry Research, Meteorological Research Institute, 1-1 Nagamine, Tsukuba, Ibaraki 305-0052, Japan

3 Oita Meteorological Office, 3-1-38 Nagahama-cho, Oita 870-0023, Japan

4 Department of Applied Physics, Faculty of Science Division 1, Tokyo University of Science, 6-3-1 Niijuku Katsushika-ku, Tokyo 125-8585, Japan

5 Information Engineering Program, Research Institute for Value-Added-Information Generation, Japan Agency for Marine-Earth Science and Technology, 3173-25 Showa-machi Kanazawa-ku, Yokohama, Kanagawa 236-0001, Japan

\section{Introduction}

Sea level can change due to a variety of factors including ocean tides, changes in ocean circulation and atmospheric pressure, and so on. In addition to such factors, coastal trapped waves (CTWs) play an important role in coastal sea level variability (e.g., Woodworth et al. 2019).

Sea level along the Japanese coast is also influenced by various processes as described above. The Kuroshio, the western boundary current of the North Pacific subtropical gyre flowing along the south coast of Japan, is one of the important factors for sea level along the Japanese coast. Its remarkable path variation has a large impact on sea level variability, especially at the south coast of Japan (Kawabe 1980; Senjyu et al. 1999; Zhang and Ichikawa 2005). Coastal sea level variations associated with propagation of CTWs induced by alongshore wind are also often observed at the Japanese coast (Kubota 1981; Kitade and Matsuyama 2000; Igeta et al. 2007). CTWs induced by strong alongshore wind due to typhoons and developed extratropical cyclones sometimes cause unusually high sea level (UHSL), which is often referred to as unusual tide 
or abnormal tide. UHSL sometimes leads to coastal flooding, if it occurs during the spring tide in autumn, when the mean sea level is generally the highest in a year.

In September 1971, a UHSL event occurred at the south coast of Japan after the passage of a typhoon. Sea level anomalies (SLAs) exceeding $30 \mathrm{~cm}$ were observed and the high sea level state continued for about half a month (Isozaki 1972; Kurashige 1972; Miyazaki 1972). It was reported that positive SLAs propagated westward along the south coast of Japan and hence continental shelf waves were one possible cause of the UHSL in September 1971 (Isozaki 1972). Several UHSL events other than the UHSL in 1971 have also been reported by previous studies (Umeki 2003; Takagi et al. 2008), in which contributions of CTWs and variations of the Kuroshio path to UHSL events in 2001 and 2006 have been discussed.

In general, it is relatively easy to identify propagating sea level signals associated with CTWs using tide gauge observations. In contrast, it is difficult to identify contributions of the Kuroshio path to a specific UHSL event. In fact, how the Kuroshio path affects coastal sea level is not well understood. In this study, we utilize a coastal assimilation model to clarify the mechanism responsible for a UHSL event that occurred in September 2011 (the 2011 UHSL, hereafter). SLAs around $30 \mathrm{~cm}$ associated with the UHSL were observed along the south coast of Japan in the end of September 2011 during the spring tide, resulting in coastal flooding in some areas. A data assimilation experiment targeting the 2011 UHSL has already been conducted by Usui et al. (2015) and it was shown that the observed features of the UHSL were well reproduced. To our knowledge, it is the first model result that reproduces an actual UHSL event.

The assimilation results suggest a possibility that a CTW induced by a fluctuation of the Kuroshio path causes the 2011 UHSL (Usui et al. 2015). This motivates us to clarify the mechanism of the 2011 UHSL using the coastal assimilation model and its assimilation results of Usui et al. (2015). In addition, generation and propagation of a CTW induced by the Kuroshio are also addressed in this study, because characteristics of wind-induced CTWs along the Japanese coast have been well studied (e.g., Kajiura 1974; Kubota 1985; Kitade and Matsuyama 2000; Tsujino et al. 2008; Igeta et al. 2007, 2015), but there have been no studies on Kuroshio-induced CTWs so far. To this end, this paper is organized as follows. Section 2 provides brief descriptions of the model and the experiment. In Sect. 3, features of coastal sea level and Kuroshio path state in September 2011 are shown on the basis of both tide gauge observations and the model results. In Sect. 4, we conduct sensitivity experiments to identify the main cause of the 2011 UHSL and the role of a CTW in the UHSL event is investigated. Section 5 gives the concluding remarks.

\section{Model and experiment}

To investigate the generation mechanism of the 2011 UHSL, a coastal assimilation system is used. It consists of a high-resolution coastal model covering around the Seto Inland Sea (Seto model) and an assimilation model for the western North Pacific based on a four-dimensional variational method (WNP-4DVAR). The Seto model is based on the Meteorological Research Institute Community Ocean Model (MRI.COM) version 3.2 (Tsujino et al. 2010). The domain of the Seto model extends from $129^{\circ}$ E to $138^{\circ} \mathrm{E}$ zonally, and from $28^{\circ} \mathrm{N}$ to $35.22^{\circ} \mathrm{N}$ meridionally (Fig. 1b). The horizontal resolution is about $2 \mathrm{~km}$ $\left(1 / 33^{\circ} \times 1 / 50^{\circ}\right)$. There are 50 vertical levels with the layer thickness increasing from $4 \mathrm{~m}$ to $600 \mathrm{~m}$. More detailed descriptions on the Seto model are given in Sakamoto et al. (2016).

Data assimilation is conducted with WNP-4DVAR, which is a 4DVAR version of the MRI Multivariate Ocean Variational Estimation (MOVE) system with the western North Pacific model (Usui et al. 2015). The western North Pacific model based on MRI.COM version 2.4 (Tsujino et al. 2006) is employed in WNP-4DVAR. The model domain extends from $117^{\circ} \mathrm{E}$ to $160^{\circ} \mathrm{W}$ zonally and from $15^{\circ} \mathrm{N}$ to $65^{\circ} \mathrm{N}$ meridionally (Fig. 1a). There are 54 vertical levels and the horizontal resolution is variable: it is zonally $1 / 10^{\circ}$ from $117^{\circ} \mathrm{E}$ to $160^{\circ} \mathrm{E}$ and $1 / 6^{\circ}$ from $160^{\circ} \mathrm{E}$ and $160^{\circ} \mathrm{W}$, and meridionally $1 / 10^{\circ}$ from $15^{\circ} \mathrm{N}$ to $50^{\circ} \mathrm{N}$ and $1 / 6^{\circ}$ from $50^{\circ} \mathrm{N}$ and $65^{\circ} \mathrm{N}$. An initialization scheme of Incremental Analysis Updates (IAU: Bloom et al. 1996) is incorporated into the Seto model. The IAU initialization is conducted periodically using WNP-4DVAR analysis results to represent actual oceanic variations.

Results of an assimilation experiment during the period from 1 August to 31 October 2011 conducted by Usui et al. (2015) are used in this study. Details of the experiment and its overall performance are described in Usui et al. (2015).

\section{Features of coastal sea level and Kuroshio path in September 2011}

\subsection{Coastal sea level}

We first discuss the observed features of the coastal sea level during the 2011 UHSL. Figure 2 shows the time series of SLAs observed at 10 tide gauge stations along the south coast of Japan (see Fig. 2a for their locations). The time series is based on daily mean SLAs, which are obtained by averaging hourly deviations from astronomical tide provided by Japan Meteorological Agency and are 
Fig. 1 Model domain and bottom topography for a WNP4DVAR and $\mathbf{b}$ Seto model. The rectangle with orange dottted line in (b) indicates a region where temperature and salinity restoring is applied in a sensitivity experiment in Sect. 4.1. The red line in (b), located along $31.5^{\circ} \mathrm{N}$, is used in a modal characteristic analysis for a coastal trapped wave in Sect. 4.2

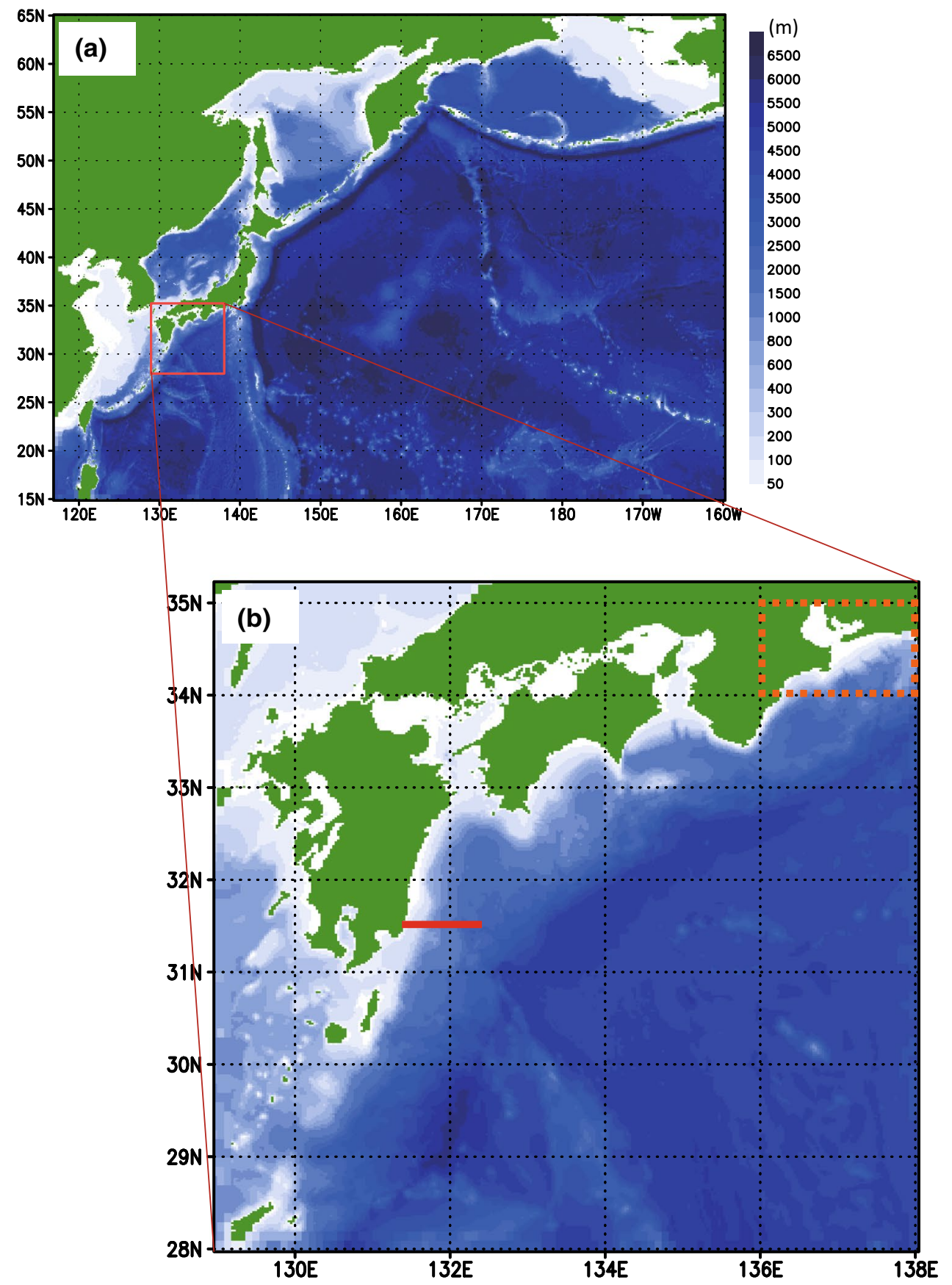

then corrected for barometric pressure. Daily mean sea level pressure observed at a meteorological weather station close to each tide gauge station is used for the barometric correction.

In the end of September, SLAs around $30 \mathrm{~cm}$ associated with the UHSL event were observed in wide areas along the south coast of Japan. It is also noticeable that abrupt sea level rises occurred around 3 September and 21 September 2011. They were caused by Typhoons Talas and Roke which made landfall in Shikoku and the main island of Japan, respectively (see Fig. 3a, b). After the passage of typhoon Roke, a high pressure system widely covered the Japanese Islands (Fig. 3c, d) and a calm weather condition continued during the period of the 2011 UHSL, implying that the increase in sea level associated with the 2011 UHSL was caused by a factor other than atmospheric forcing.

Taking a close look at the sea level variations at the tide gauge stations, we find a slight difference in variations of sea level between the western and the eastern part of Japan. To be specific, sea level rise associated with the 2011 UHSL occurs roughly twice in the western part of Japan. The first one occurs around 15 September 2011, and it is especially 
Fig. 2 a Locations of ten tide gauge stations along the south coast of Japan. Names of the tide gauge stations in the western (eastern) part of Japan are shown in the legends on the left (right). Their colors correspond to those of filled squares indicating tide gauge locations. Time series of observed sea level anomalies from 1 September to 16 October at tide gauge stations in the $\mathbf{b}$ western and $\mathbf{c}$ eastern part of Japan. Line colors are the same as those for tide gauge locations in (a) (a) Tide gauge locations

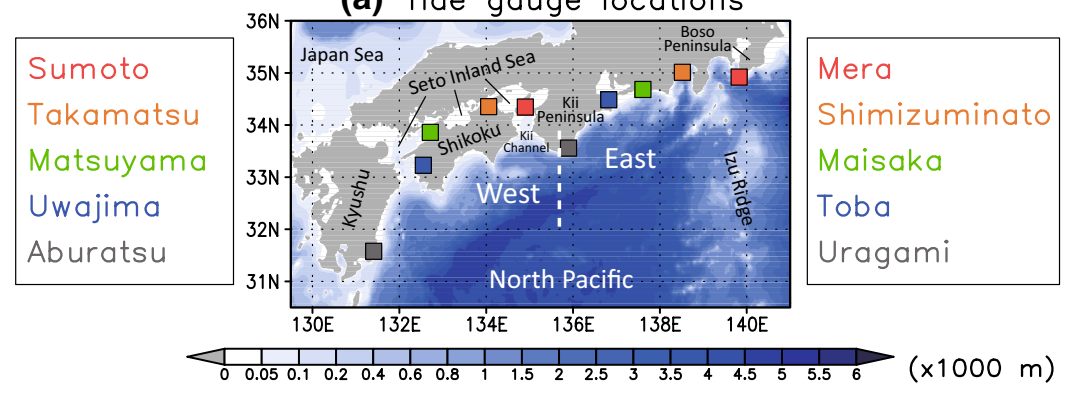

(b) Western Japan

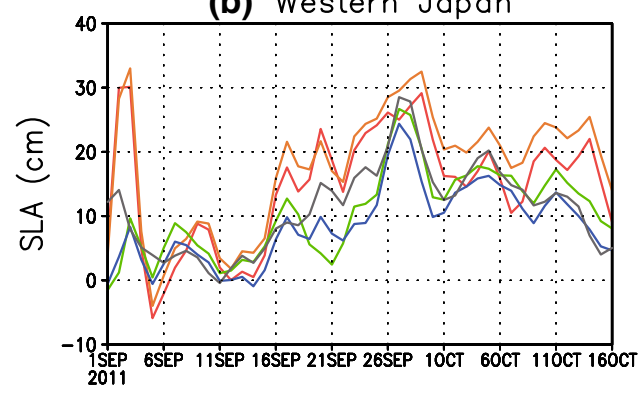

(a)

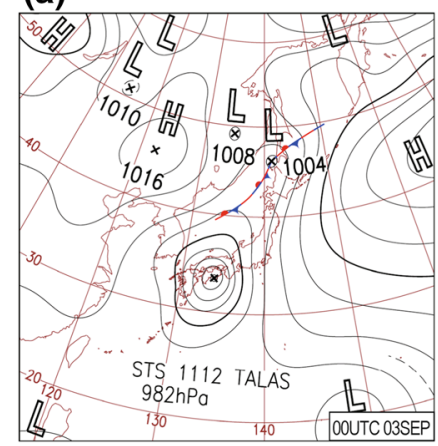

(b)

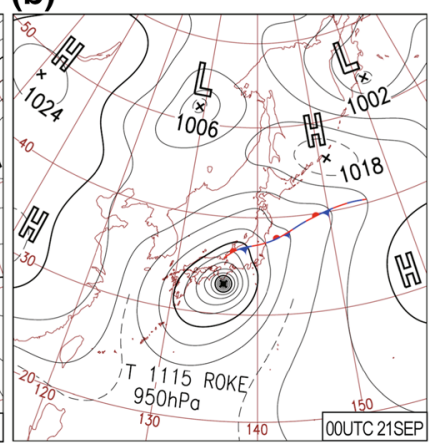

(c)

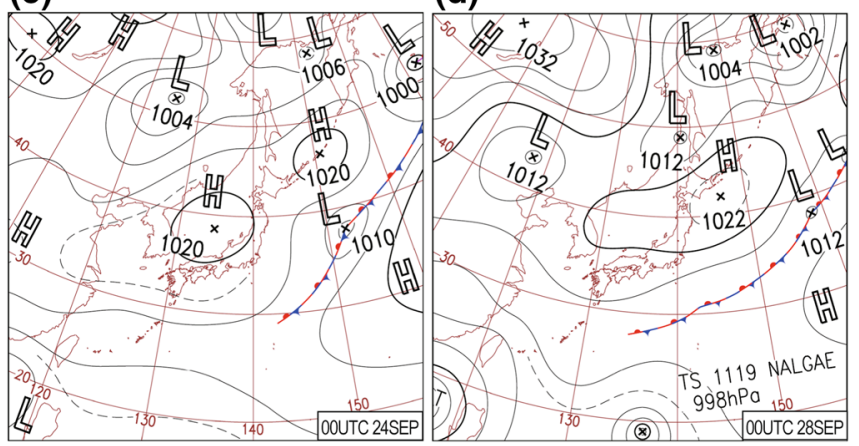

Fig. 3 Surface weather charts at 00UTC: a 3 September, b 21 September, c 24 September, and d 28 September 2011, which were obtained from the website of Japan Meteorological Agency (http://www.data.jma.go.jp/fcd/yoho/hibiten/)

prominent in the eastern part of the Seto Inland Sea such as Sumoto and Takamatsu. The second one is from 22 to 28 September 2011. In the eastern part of Japan, on the other hand, the increase in sea level associated with the UHSL event occurs only once in the end of September, which is the same timing as that of the second sea level rise in the western part of Japan.

A Hovmöller diagram in Fig. 4b, showing tide gauge SLAs along the Japanese coast from 21 September to 5 October, suggests one possible cause for the second sea level rise. In the diagram, a high sea level signal seems to propagate westward along the south coast of Japan in the end of September. The westward propagation of SLAs is more distinct in Fig. 4c, which displays time change of sea level anomaly $d(\mathrm{SLA}) / d t$, although propagation is unclear at Gobo and Awayuki (\#9 and \#10 in Fig. 4a) located around the Kii Channel. The above results imply that a coastal trapped wave (CTW) propagated along the south coast of Japan in the end of September 2011. SLAs at south coast of Japan are considered to include various signals due to not only CTWs, but also other factors such as variations of the Kuroshio and associated coastal currents. Taking the time change of SLA in Fig. $4 \mathrm{c}$ is thus intended to extract propagation signals along the coast, whose time scale is generally shorter than those for variations of the Kuroshio. If we assume that the propagation distance and time between Kushimoto and Hamada (\#8 and \#18 in Fig. 4a) are roughly $1200 \mathrm{~km}$ and 4-5 days, the propagation speed is estimated at $2.78-3.47 \mathrm{~m} \mathrm{~s}^{-1}$. 
Fig. 4 a Locations of 20 tide gauge stations and Hovmöller diagrams along the 20 tide gauge stations for $\mathbf{b}$ sea level anomaly (unit in $\mathrm{cm}$ ) and $\mathbf{c}$ time change of SLA (unit in $\mathrm{cm} / 2$-day)

(a) Tide gauge locations

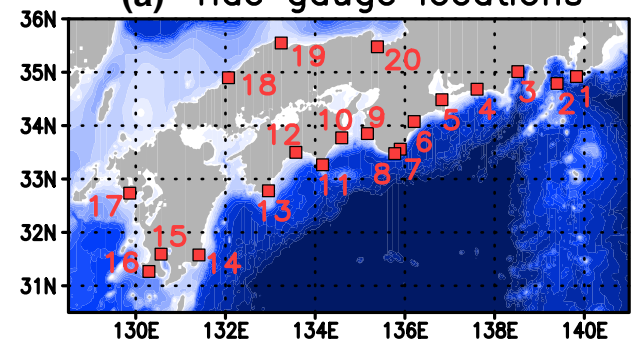

(b) Sea level anomaly

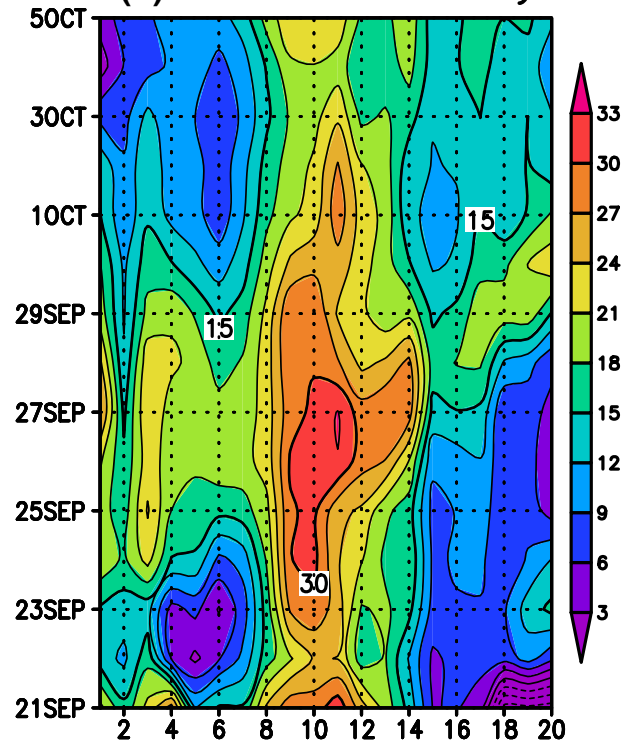

(c) $d(S L A) / d t$

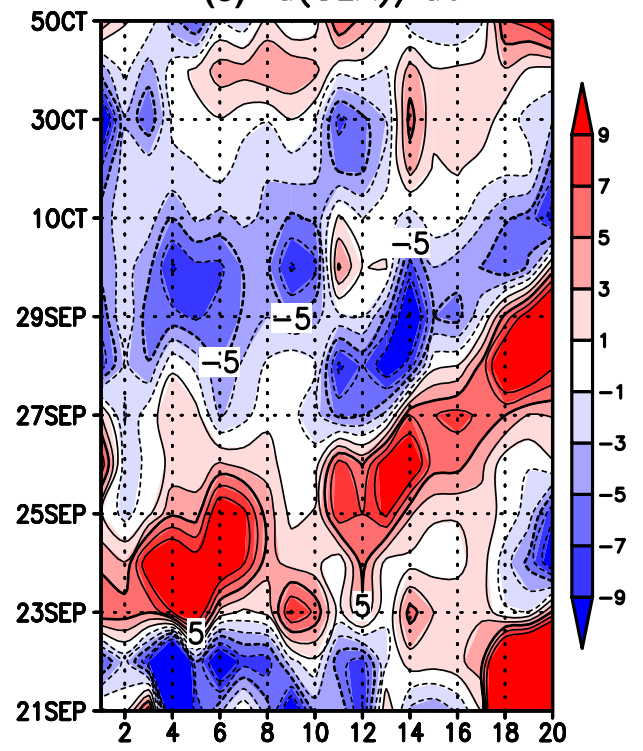

(e) $d(S L A) / d t$

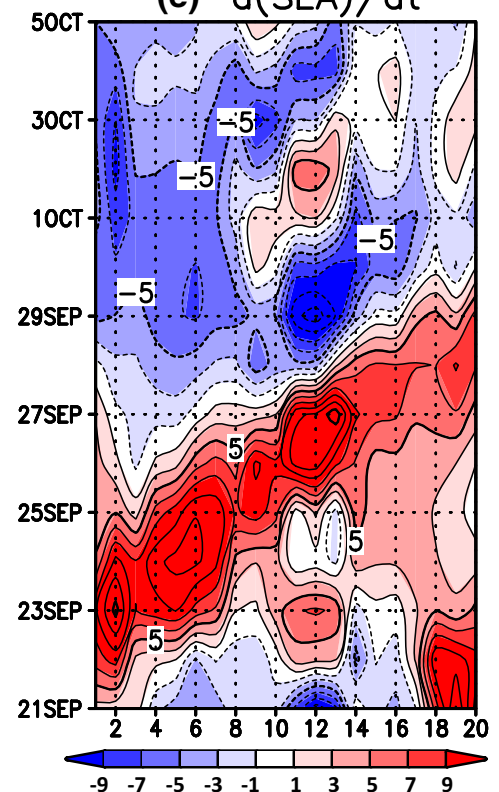

Fig. 5 a-d Time series of SLAs from 1 September to 5 October at tide gauge stations a Toba, b Sumoto, c Uwajima, and d Aburatsu. e Same as Fig. 4c, but based on the model result (unit in $\mathrm{cm} / 2$-day). Black solid line with open circles and red solid line in (a-d) indicate SLAs for observation and model, respectively. The SLAs for the model result are defined as anomalies from daily climatological $\mathrm{SSH}$ from 1993 to 2007. In addition, a correction factor is added to the model SLA so that a time average value is equal to that for observation at each tide gauge station 
SLAs for the Seto model in the assimilation experiment are compared to those for observations at four tide gauge stations along the south coast of Japan (Fig. 5a-d). The model SLAs are defined as deviations from a climatological annual cycle of SSH field in 1993-2007, which was obtained from a reanalysis experiment based on 3DVAR with the WNP model (Usui et al. 2006). In addition, we add correction factors to the model SLAs in Fig. 5 so as to make the time average between 1 September and 5 October equal to those for the tide gauge observations. Although there is a phase lag for the peak of the sea level rise in the end of September, the assimilation result largely captures observed features of the coastal sea level variations. A similar phase lag is found in SLA at Miyake-jima located to the south of the tide gauge station \#2 (not shown). The lag at Miyake-jima is attributed to a delay of Kuroshio meander's movement in WNP4DVAR and it is thus one possible cause for the phase lag.

To compare with Fig. 4c, a Hovmöller diagram of time change of SLA based on the assimilation result is shown in Fig. 5e. SLA at each tide gauge station is calculated by linear interpolation from the model grid. It should be noted that SLAs at tide gauge stations \#4-\#18 (\#1-\#3, and \#19-\#20) are based on the Seto model (WNP-4DVAR). A propagation signal in the end of September is apparent in the model result like in the observation. There is, however, a discrepancy in the propagation feature between the model and observation. The discontinuity around the Kii Channel seen in the observation is not found in the model result. This might be related to reproducibility of circulation feature in the Kii Channel. The observed SLA in Fig. $4 \mathrm{~b}$ is the highest around the Kii Channel and it exceeds $30 \mathrm{~cm}$ in 24-27 September, implying that the Kuroshio axis to the south of Cape Shionomisaki was located close to the coast and a northwestward counter current along the southwest coast of the Kii Peninsula was developed. The assimilation result also shows that the Kuroshio takes a nearshore path around the Cape Shionomisaki in the end of September, but the northwestward counter current is not so strong when the propagation signal arrives at the Kii Channel (not shown). That is probably why the propagation signal at the Kii Channel is clear in the model result. If the counter current along the southwest coast of the Kii Peninsula is developed, the propagation signal at the Kii Channel would be contaminated by signals associated with changes in the counter current. This may have been the case in reality and might be a possible cause for the discontinuity at the Kii Channel in observation. Furthermore, the discrepancy in the propagation feature at the Kii Channel might also affect the phase lag at the tide gauges in the western part of Japan such as Uwajima and Aburatsu (Fig. 5c, d).

\subsection{Kuroshio path state south of Japan}

In this subsection, we focus on the Kuroshio path state south of Japan in September 2011 and its relation to the significant sea level rise associated with the UHSL event. Figure 6 shows time evolution of the model SSH map, which (a) 14SEP2011

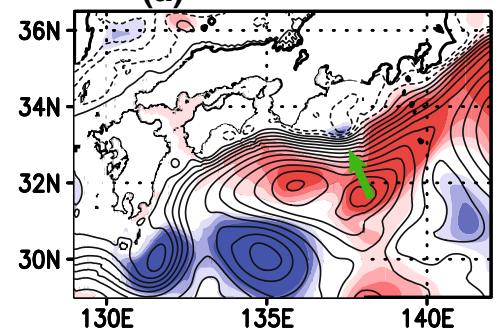

(d) 23SEP 2011

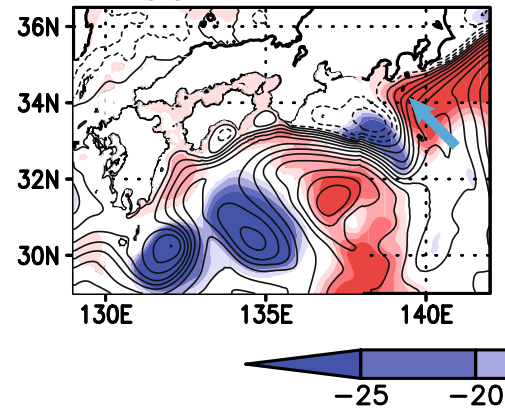

(b) 17SEP2011

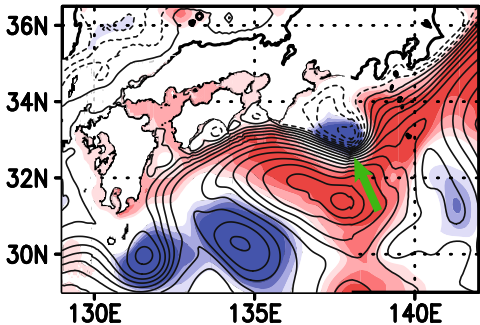

(e) 26SEP 2011

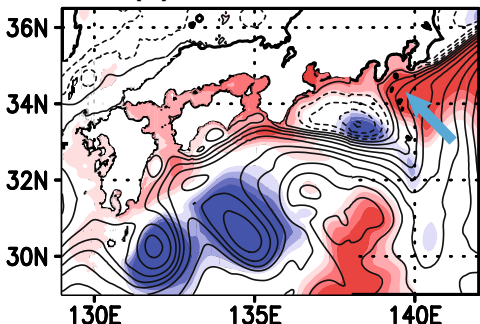

(c) 20SEP2011

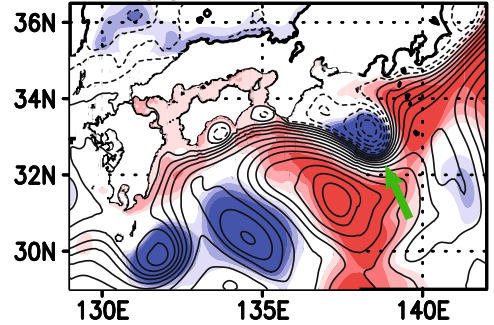

(f) 29SEP2011

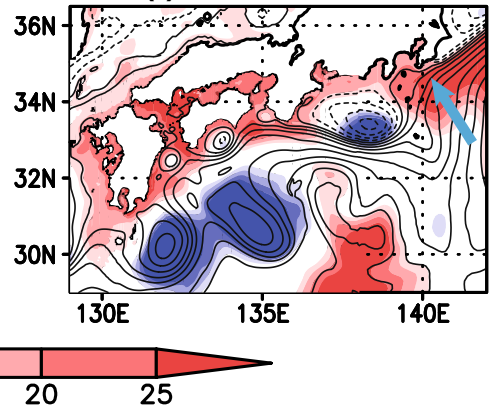

Fig. 6 Time evolution of (contour) SSH and (shade) SSH anomaly from the middle to the end of September 2011 (unit in cm). The SSH contours are drawn with an interval of $10 \mathrm{~cm}$. Green arrows in $(\mathbf{a}-\mathbf{c})$ indicate evolution of a meander accompanying negative SSH anomalies of interest. Light blue arrows in $(\mathbf{d}-\mathbf{f})$ point to a crest to the east of the meander 
suggests a cause of the sea level rise in the end of September. It should be noted that the SSH map for the Seto model is superimposed on that for WNP-4DVAR and the correction factors added to the SLAs in Fig. 5 are not considered in Fig. 6.

The Kuroshio takes a straight path on 14 September (Fig. 6a), while a small-scale disturbance accompanying negative SSH anomalies is located to the southeast of the Kii Peninsula. The disturbance then moves eastward along the Kuroshio and forms a meander (see green arrows in Fig. 6a-c). The crest of the meander accompanying positive SSH anomalies denoted by light blue arrows in Fig. 6d-f consequently approaches the southern tip of the Boso Peninsula (see Fig. 2a for geographical location). As a result, the significant increase in sea level occurs at the south coast of Japan (Fig. 6e, f) and a part of the positive SLAs goes into the coast of the Japan Sea. The above result suggests that propagation of a CTW caused by the short-term fluctuation of the Kuroshio path is one possible cause of the second sea level rise in the end of September 2011. It is consistent with the observed features as described in the previous subsection. In addition, we confirmed that a Hovmöller diagram of time change of SLA based on the model result clearly shows propagation of the CTW like Fig. 4c (not shown). The contribution of the CTW to the 2011 UHSL will be further investigated in the next section with sensitivity experiments.

Next, we look at variations of the Kuroshio path to the south of the Kii Peninsula and its relation to the first sea level rise in the western part of Japan around 15 September 2011. As shown in Fig. 6, the Kuroshio flowed very close to Cape Shionomisaki, located at the southern tip of the Kii Peninsula, in September 2011. To take a close look at Kuroshio path variations there, time evolution of the surface velocity field for the Seto model is displayed in Fig. 7. The surface Kuroshio axis to the south of the Kii Peninsula slightly migrates north toward Cape Shionomisaki (see velocity magnitude around Cape Shionomisaki). As a result, northwestward counter current appears along the southwest coast of the Kii Peninsula (Fig. 7b). The counter current then develops to form a cyclonic circulation in the Kii Channel (Fig. 7c).

The northward migration of the Kuroshio axis can be confirmed more clearly from time-latitude section of $400 \mathrm{~m}$ temperature along $135.5^{\circ} \mathrm{E}$ shown in Fig. 8b. Large meridional temperature gradient between 10 and $15^{\circ} \mathrm{C}$, which corresponds to the main part of the Kuroshio current, obviously migrates northward in the middle of September 2011. The northward migration of the Kuroshio in the model result is

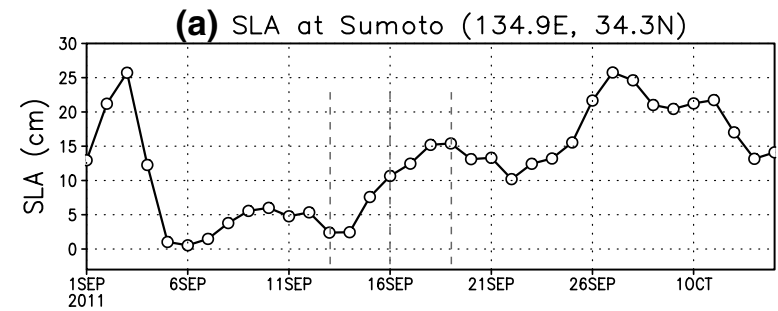

(b) T400 along $135.5 \mathrm{E}$

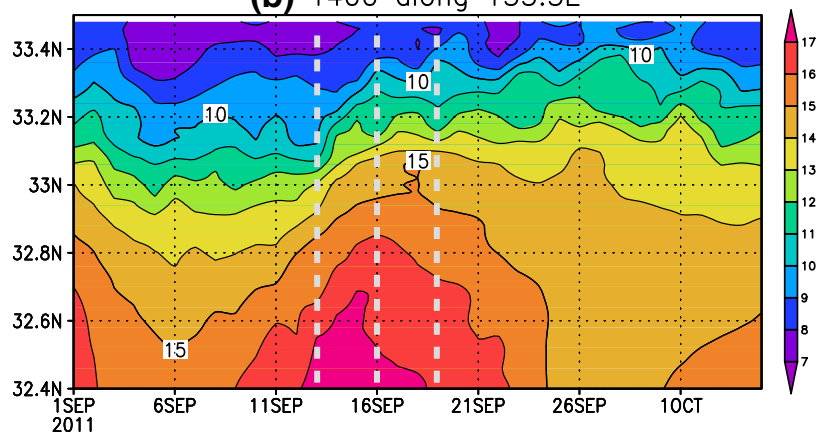

Fig. 8 a Time series of SLA at Sumoto for the Seto model. b Timelatitude section of $400 \mathrm{~m}$ temperature along $135.5^{\circ} \mathrm{E}$. Three vertical dashed lines indicate time corresponding to 13,16 , and 19 September 2011, respectively (a) 13SEP2011

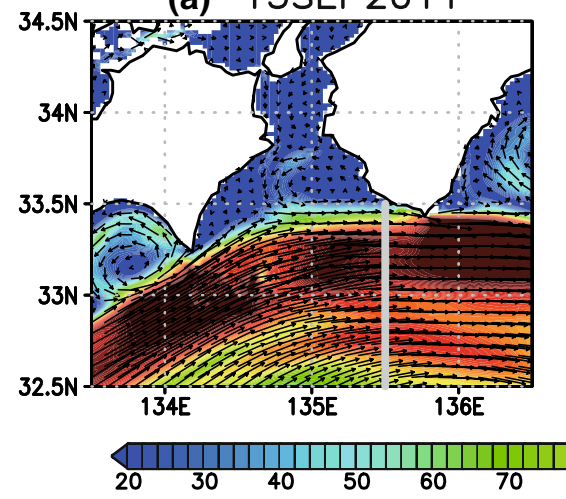

(b) 16SEP2011

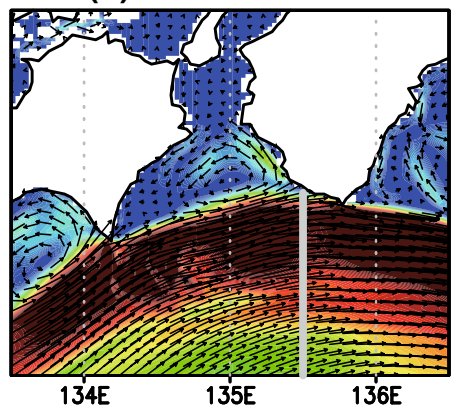

(c) 19SEP2011

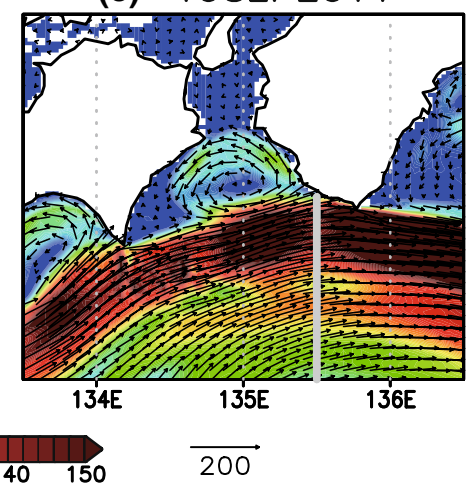

Fig. 7 Time evolution of surface current around the Kii Channel in the middle of September 2011 (unit in $\mathrm{cm} \mathrm{s}^{-1}$ ). Gray lines indicate location of the latitudinal section along $135.5^{\circ} \mathrm{E}$ in Fig. $8 \mathrm{~b}$ 
supported by tide gauge observations, which show that sea level difference between Kushimoto and Uragami is intensified in the middle of September, indicating that the Kuroshio axis moves northward (not shown). It is worth noting that sea level rise in the middle of September at Sumoto, which is located to the north of the Kii Channel (see Fig. 2a), is well synchronized with the northward migration of the Kuroshio (Fig. 8a), implying that the sea level rise in the middle of September is caused by the northward migration of the Kuroshio axis south of the Kii Peninsula.

Difference in sea level between before and after the northward migration of the Kuroshio axis shown in Fig. 9 illustrates the impact of the Kuroshio's migration on the increase in sea level around the Kii Channel more clearly. Sea level is elevated along the rim of the cyclonic circulation in the Kii Channel due to supply of warm Kuroshio water. The positive change in sea level extends into the eastern part of the Seto Inland Sea. It would be understood as a dynamical response of the sea level rise in the Kii Channel. The positive change of sea level in the eastern part of the Seto Inland Sea is consistent with the observed fact that the sea level rise in the middle of September is prominent in the eastern part of the Seto Inland Sea such as Sumoto and Takamatsu (Fig. 2b). The above result suggests the importance of the cyclonic

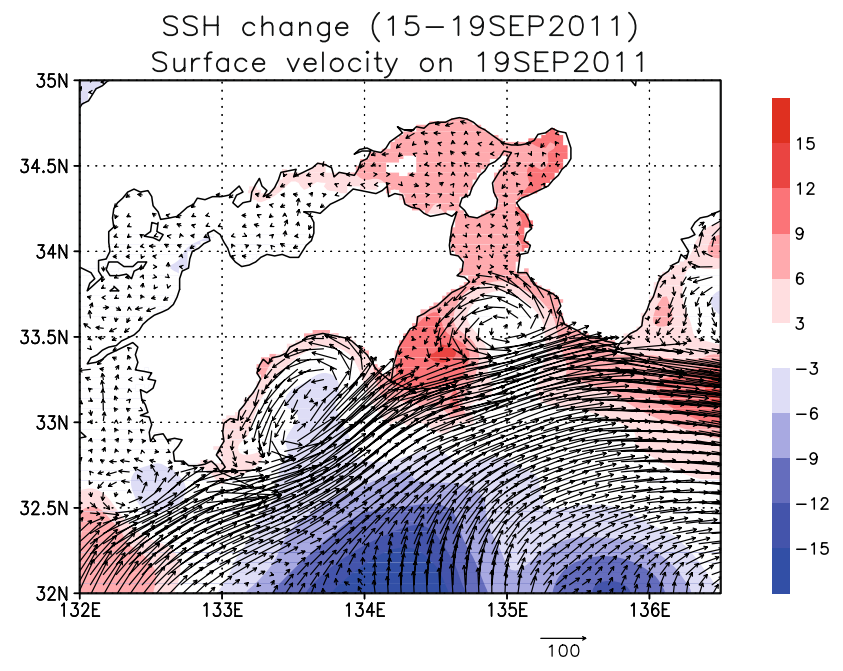

Fig. 9 Change in SSH (unit in $\mathrm{cm}$ ) from 15 to 19 September and surface velocity (unit in $\mathrm{cm} \mathrm{s}^{-1}$ ) on 19 September 2011 circulation in the Kii Channel formed as a counter current of the Kuroshio for the sea level rise not only in the Kii Channel but also in the eastern part of the Seto Inland Sea.

\section{Role of coastal trapped wave in the unusually high sea level}

In the previous sections, we discussed the possibility that the CTW induced by the fluctuation of the Kuroshio path caused the sea level rise in the end of September 2011. In this section, we conduct sensitivity experiments to make clear the contribution of the CTW to the 2011 UHSL, and investigate characteristics of the CTW induced by the Kuroshio.

\subsection{Sensitivity experiments}

We conduct four experiments (CTRL, xTYPH, xCTW, and $\mathrm{xCTW}$ 2) using the Seto model, which are summarized in Table 1. It should be noted that data assimilation is not applied to the Seto model in each experiment to make it easy to understand the results of the experiments. In the CTRL experiment, a hindcast simulation is carried out during the period 20 July to 31 October 2011. Its initial condition is obtained from the assimilation result. Atmospheric forcing used is JRA-25/JCDAS, and boundary conditions are obtained from the WNP-4DVAR assimilation results. SLA at Sumoto in CTRL is compared with observation in Fig. 10. The sea level rise associated with the UHSL event in the end of September, which is the main target of this section, is well represented in CTRL. In contrast, the sea level rise in the middle of September is not reproduced, because the model Kuroshio path is located slightly south of the Kii Peninsula and hence the cyclonic circulation in the Kii Channel is not formed (not shown).

To investigate the contribution of Typhoon Roke, which made landfall in the central part of Japan on 21 September 2011 (see Fig. 3), a hindcast simulation is conducted with daily climatological forcing during the same period as CTRL. The daily climatological forcing is calculated by averaging JRA-25/JCDAS over 1981-2010. Other conditions such as initial and boundary conditions are the same as those for CTRL. The sea level rise in the end of September is reproduced in XTYPH even though the typhoon
Table 1 List of the sensitivity experiments

\begin{tabular}{|c|c|c|}
\hline Exp. name & Forcing & Commments \\
\hline CTRL & JRA-25/JCDAS & Reference hindcast simulation (21 July to 31 October 2011) \\
\hline xTYPH & Daily climatology & $\begin{array}{l}\text { Atmospheric forcing is replaced by daily climatology to investi- } \\
\text { gate impacts of typhoons }\end{array}$ \\
\hline $\mathrm{xCTW}$ & JRA-25/JCDAS & TS restoring is applied to damp the CTW signals \\
\hline xCTW2 & JRA-25/JCDAS & Eastern boundary conditions are fixed to those on 11 September \\
\hline
\end{tabular}




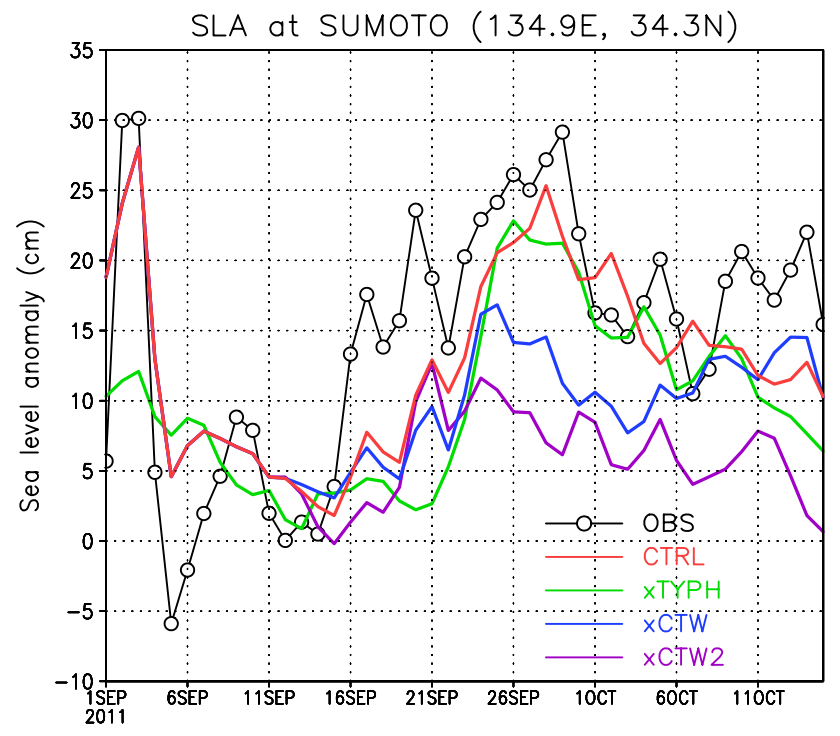

Fig. 10 Time series of SLAs at Sumoto for (black line with open circle) observation, (red) CTRL, (gree) xTYPH, (blue) xCTW, and (purple) $\mathrm{xCTW} 2$

is not included in the atmospheric forcing data. This result indicates that Typhoon Roke does not directly contribute to the second sea level rise in the end of September 2011.

The experiments of $\mathrm{xCTW}$ and $\mathrm{xCTW} 2$ are intended to make clear the contribution of the CTW to the sea level rise in the end of September 2011. The experimental conditions for $\mathrm{xCTW}$ are the same as those for CTRL, but nudging of temperature and salinity is applied within the rectangle region $\left(136^{\circ}-138^{\circ} \mathrm{E}, 34^{\circ}-35.1^{\circ} \mathrm{N}\right)$ near the northeastern corner of the model domain (see Fig. 1b) to damp signals related to the CTW. The nudging works after 11 September, and temperature and salinity within the rectangle region are nudged toward temperature and salinity on 11 September with a time scale of 1 day. As shown in Fig. 10, the sea level rise in the end of September for $\mathrm{xCTW}$ is mitigated compared to that for CTRL. The sea level at Sumoto for $\mathrm{xCTW}$, however, increases by more than $10 \mathrm{~cm}$ during $15-25$ September, which is about half of the sea level rise in CTRL. We looked into the model results to identify the cause of the sea level rise in xCTW. A minor sea level increase in 15-21 September, which does not propagate westward, seems to be caused by southerly winds and approaching typhoon (see Fig. 3). In fact, it does not occur in XTYPH. In contrast, SSH signals related to the increase after 22 September come from the eastern boundary and propagate as CTW (not shown). This is because the propagating SSH signals associated with the CTW are not completely damped by the temperature and salinity nudging in $\mathrm{xCTW}$ and some portion remains. In fact, the sea level rise after 22 September hardly occurs in $\mathrm{xCTW} 2$, where, instead of the nudging, eastern boundary conditions are fixed to those on 11 September to extinguish
CTW signals. Considering the above, we conclude that the main factor for the sea level rise in the end of September is propagation of the CTW induced by the Kuroshio. In the next subsection, characteristics of the CTW induced by the Kuroshio will be further investigated using the results of the sensitivity experiments.

\subsection{Characteristics of coastal trapped wave induced by Kuroshio}

Difference in SSH fields between CTRL and XCTW can be regarded as SSH signals associated with CTW. In fact, time evolution of the SSH difference (CTRL minus xCTW) in Fig. 11a shows that $\mathrm{SSH}$ signals with positive anomalies propagate along the south coast of Japan as in Fig. 6. We decompose the SSH signals into steric and non-steric components, which are shown in Fig. 11b, c. The steric component represents SSH signals related to changes in seawater density, and the non-steric component arises from changes in bottom pressure. Their calculation method is described in Appendix A.

As shown in Fig. 11b, c, there are characteristic differences between steric and non-steric SSH signals. The steric signals propagate along the continental slope south of Japan. On the other hand, the non-steric signals with positive anomalies are confined in coastal areas typically shallower than $200 \mathrm{~m}$ (see green contours in Fig. 11). In addition, the non-steric signals are accompanied by negative anomalies in offshore side. Since non-steric SSH variations arise from changes in mass of the water column, the negative anomalies can be understood as a response to SSH increase in the shallow region so as to conserve total ocean mass. The above result suggests that the propagating SSH signals possess characteristics of both baroclinic Kelvin wave and barotropic shelf wave, which are transformed into each other according to topographic features.

The SSH signals in the Seto Inland Sea are dominated by the non-steric component. This is because the steric one does not enter the Seto Inland Sea and goes along the continental slope south of Shikoku as mentioned above. It is therefore interesting how the non-steric SSH signals in the Seto Inland Sea are generated and are related to the steric ones. The non-steric SSH signals first appear in the eastern part of the Seto Inland Sea when the steric ones reach the Kii Channel (Fig. 11b,c). This is similar to the sea level rise in the eastern part of the Seto Inland Sea in the middle of September, which was explained as a dynamical response of the sea level rise in the Kii Channel due to supply of warm Kuroshio water by the cyclonic circulation. The sea level in the western part of the Seto Inland Sea, in contrast, increases when the steric SSH signals reach the Bungo Channel located between Kyushu and Shikoku (Fig. 11b, c). These results suggest that sea level in the Seto Inland Sea 

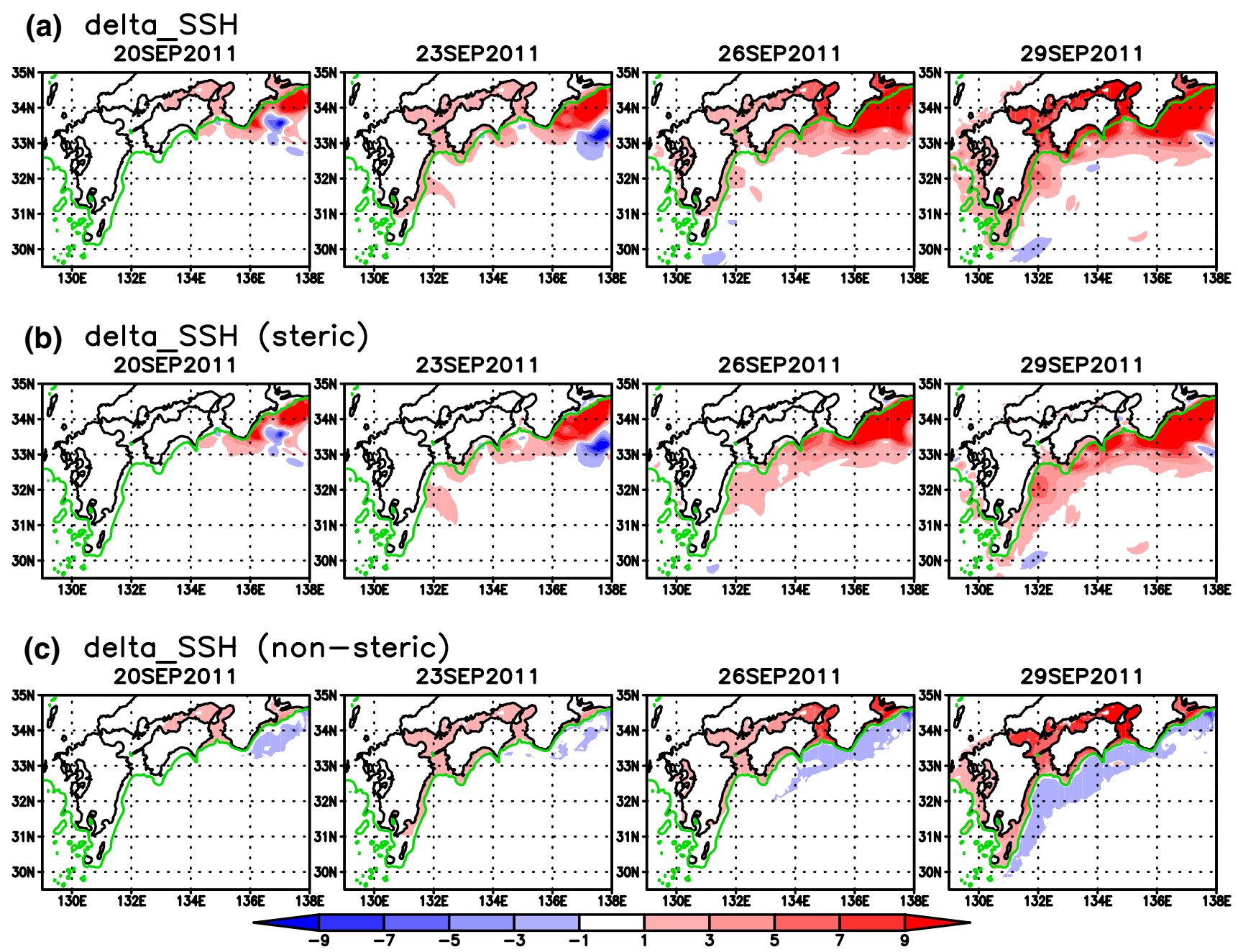

Fig. 11 a Time evolution of difference in SSH fields between CTRL and xCTW (CTRL minus xCTW). The SSH difference is decomposed into b steric and c non-steric components (unit in $\mathrm{cm}$ ). Green lines indicate $200 \mathrm{~m}$ isobath

is sensitive to that in the Kii and Bungo Channels, implying that baroclinic SSH signals in the Channels tend to be transformed into barotropic ones in the shallow Seto Inland Sea.

In the Japan Sea, which is also semi-enclosed and connects to adjacent seas through narrow and shallow straits like the Seto Inland Sea, similar barotropic adjustment has been reported to occur and to affect volume transport through the straits (Ohshima 1994; Kida et al. 2016). Kida et al. (2016) suggested that baroclinic SSH signals associated with windinduced Kelvin waves are transformed into barotropic ones at the shelf around the Soya Strait and consequently surface gravity waves are excited in the Japan Sea, resulting in the barotropic adjustment in the Japan Sea. The non-steric SSH signals in the Seto Inland Sea would be understood in the same manner as those in the Japan Sea.

To look into vertical structures of the propagating CTW signals, we take difference between CTRL and xCTW results along a zonal section at $31.5^{\circ} \mathrm{N}$ southeast of Kyushu (see the red line in Fig. 1b). Vertical structures of alongshore (meridional) velocity and density anomalies related to the CTW are shown in Fig. 12a, e. The figures show a difference of 5-day mean fields for the two experiment from 26 September to 30 September, when the CTW reaches southeast of Kyushu. Southward (alongshore) current is intensified due to the CTW (Fig. 12a). The intensification of the southward current is concentrated in the surface to subsurface layers near the coast. Anomalies in density associated with the CTW are negative in almost layer and are also prominent in the surface to subsurface layers, which largely correspond to the thermocline depth, indicating that the thermocline deepens due to the CTW.

To further understand the vertical structure of the CTW, we conduct a modal characteristic analysis of CTWs. The calculation details are presented in Appendix B. Vertical structures of the calculated leading three modes for the alongshore velocity and density are shown in Fig. 12b-d, 

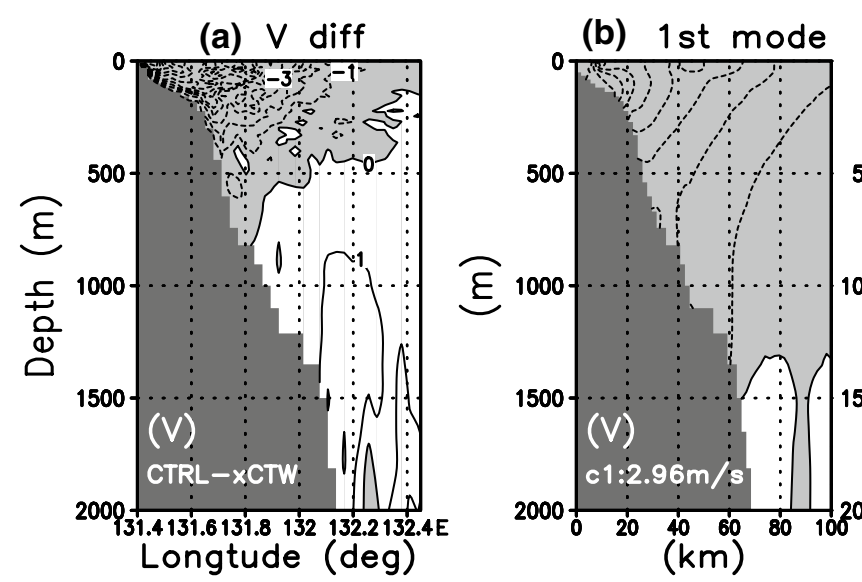

(c) 2nd mode

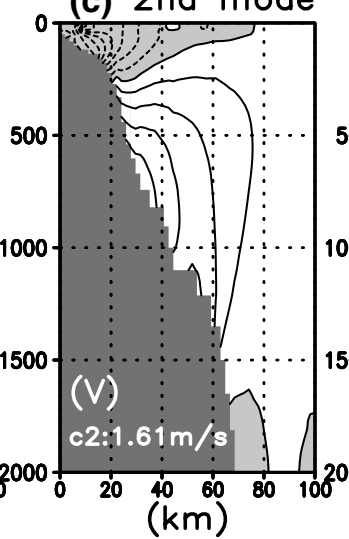

(d) 3rd mode

(e) RHO diff
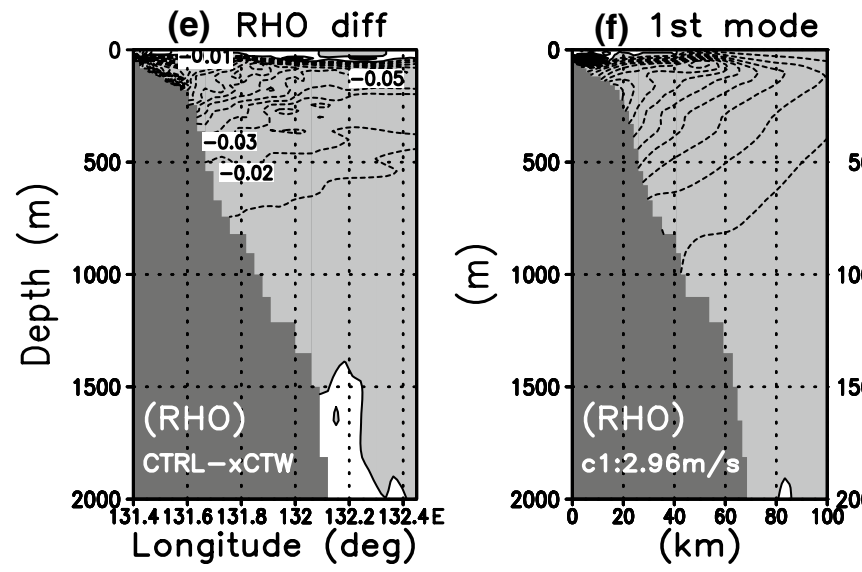

(g) 2nd mode
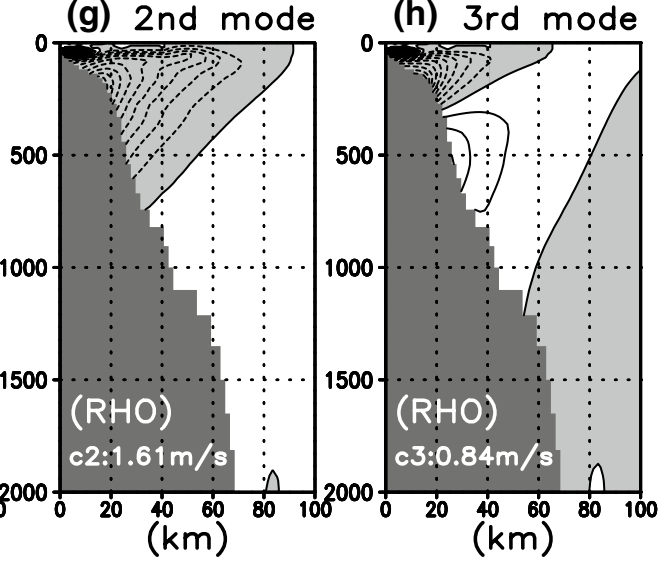

Fig. 12 Vertical structures of anomalies for a meridional velocity (unit in $\mathrm{cm} \mathrm{s}^{-1}$ ) and $\mathbf{e}$ density (unit in $\mathrm{g} \mathrm{cm}^{-3}$ ) calculated as differences between CTRL and xCTW along a zonal section at $31.5^{\circ} \mathrm{N}$ southeast of Kyushu (see Fig. 1b). Vertical structures of the leading three modes calculated from the modal characteristic analysis are

shown in (b-d) and (f-h) for alongshore velocity and density, respectively (unit arbitrary). Note that the $\mathrm{x}$-axis in (b-d) and (f-h) denotes zonal distance from $\left(131.4^{\circ} \mathrm{E}, 31.5^{\circ} \mathrm{N}\right)$. Calculated phase speed for each mode is also shown. Light gray shading indicates negative values

f-h, respectively. The alongshore velocity (Fig.12b) and density (Fig.12f) anomalies for the first mode are prominent in the upper layers and the sign of the density anomaly is the same in the whole layer. These characteristics for the first mode are similar to those of the model results. The anomalies for the alongshore velocity and density in the model results are however more concentrated in shallow layers compared to those for the first mode, suggesting contributions of higher modes.

The phase speeds of the leading three modes are calculated to be $2.96 \mathrm{~m} \mathrm{~s}^{-1}, 1.61 \mathrm{~m} \mathrm{~s}^{-1}, 0.84 \mathrm{~m} \mathrm{~s}^{-1}$, for the first, second, and third modes, respectively. The phase speed of $2.96 \mathrm{~m} \mathrm{~s}^{-1}$ for the first mode compares well with the tide gauge-based estimate $\left(2.78-3.47 \mathrm{~m} \mathrm{~s}^{-1}\right)$ in Sect. 3.1, indicating that the first mode is the most dominant. It should be noted that background flow is not taken into account in the calculated modal characteristics as described in Appendix B. It is however possible that the modal characteristics such as phase speed are modulated by background Kuroshio flow when the Kuroshio current exists near the coast, like around Cape Muroto and Cape Shionomisaki (see Fig. 7). Such an effect, therefore, should also be considered for more quantitative evaluation.

Difference in the phase speeds of the leading modes implies that the sea level rise first occurs due to the first mode CTW and contributions of the second and higher modes increase subsequently. Looking at the time series of SLA at Sumoto (Fig. 10) in detail, we can find in both observation and CTRL that rapid sea level rise in the end of September occurs twice around 22-26 and 27-29 September, although the second one is unclear in XTYPH. These might be related to contributions of the first and the higher modes, respectively. In fact, velocity anomalies associated with the CTW at the zonal section southeast of Kyushu are intensified in surface layers with time during the CTW propagation, and the depth at which the sign of the velocity anomaly is inverted becomes shallower, indicating the increased contributions of the higher modes (not shown). Furthermore, the 
sea level rise in the end of September for xCTW in Fig. 10 would also be interpreted in conjunction with the modal characteristics of the CTW. As mentioned in the previous subsection, the SSH signals associated with the sea level rise in the end of September for XCTW come from the eastern boundary despite the temperature and salinity nudging, because the propagating CTW signals are not completely damped by the nudging and some portion remains. The sea level rise during 22-25 September, which is considered due to the contribution of the first mode CTW, is prominent for xCTW but the sea level drops after that. It suggests that the first mode CTW tends to survive the nudging and that the higher modes are damped more effectively due to slow phase speed.

According to Brink (1982) and Brink and Chapman (1987), the ratio of the kinetic energy (KE) to the potential energy (PE), KE/PE, is useful to diagnose the character of a generalized long free coastal trapped wave. It approaches 1 for a baroclinic Kelvin-like wave, while it becomes large (> 10) for a barotropic shelf wave. The ratio is calculated to be $2.51,2.21$, and 1.33, for the first, second, and third modes, respectively, suggesting that the CTW possesses the character of a baroclinic Kelvin wave in the region southeast of Kyushu. This is consistent with the fact that SSH signals associated with the CTW are dominated by the steric component and accompanied by prominent density anomalies in the ocean interior southeast of Kyushu.

\section{Concluding remarks}

By using a coastal assimilation model, the generation mechanism of the UHSL event in September 2011 (the 2011 UHSL) was investigated. In an assimilation experiment, the model succeeded in reproduction of variations in coastal sea level associated with the 2011 UHSL. Both the model result and tide gauge observations indicate that sea level rise occurred twice in the middle and end of September. The first one in the middle of September is localized around the eastern part of the Seto Inland Sea. The second one in the end of September, which is the main contributor to this event, was observed in wide areas not only at the south coast of Japan, but also at the coast of the Japan Sea. SLAs in the end of September were mostly $20-30 \mathrm{~cm}$ and the largest anomalies exceeding $30 \mathrm{~cm}$ were observed in the eastern part of the Seto Inland Sea. This could be because sea level rise occurred twice around the eastern part of the Seto Inland Sea in contrast to only once in other areas.

On the basis of the assimilation experiment and a series of sensitivity experiments, we clarified the mechanism for the above two processes associated with the 2011 UHSL, which are summarized in Fig. 13. The sea level increase in the middle of September is triggered by northward migration of the Kuroshio axis toward Cape Shionomisaki located at the southern tip of the Kii Peninsula. As a result of the northward migration of the Kuroshio, northwestward counter current appears along the southwest coast of the Kii Peninsula, developing into a cyclonic circulation in the Kii Channel. The cyclonic circulation brings warm Kuroshio water into the Kii Chanel and consequently causes the sea level rise around the Kii Channel including the eastern part of the Seto Inland Sea.

The sea level rise in the end of September is brought about by a CTW, which is induced as a result of a fluctuation of the Kuroshio path to the south of the Boso Peninsula. The fluctuation first appears southeast of the Kii Peninsula and then propagates along the Kuroshio, resulting in a meander to the south of the Boso Peninsula. The generation and development of the fluctuation of the Kuroshio might be related to the mechanism proposed by Miyama and Miyazawa (2014), who suggest that short-term fluctuations of the Kuroshio downstream of Cape Shionomisaki are

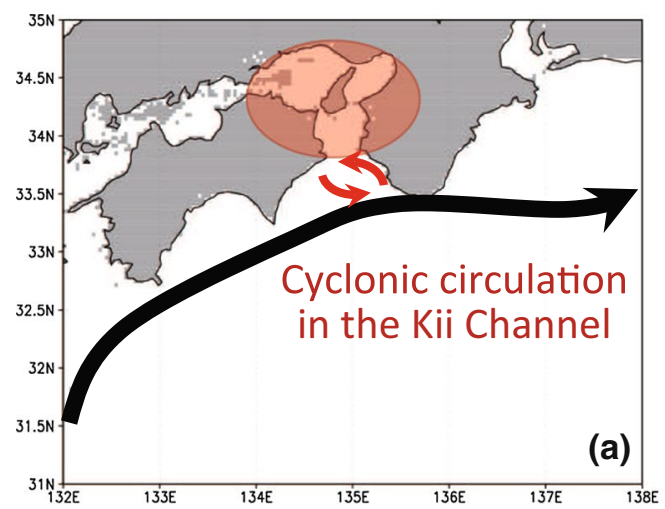

Fig. 13 Schematic diagrams of the proposed mechanisms for the UHSL in September 2011 showing a local sea level rise around the eastern part of the Seto Inland Sea due to formation of a cyclonic cir-

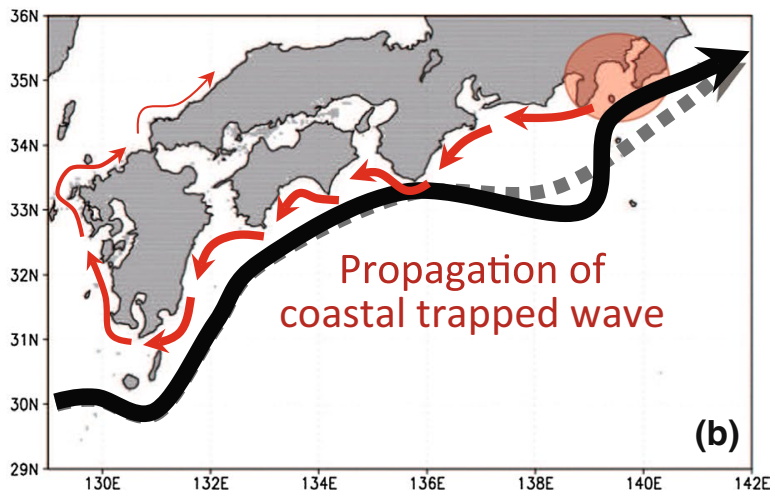

culation in the Kii Channel, and $\mathbf{b}$ sea level rise due to propagation of a CTW induced by a fluctuation of the Kuroshio path south of Boso Peninsula 
intensified due to topography-induced instability during the period of a nearshore Kuroshio path.

The CTW with positive SSH anomalies propagates westward along the south coast of Japan, and then goes into the coast of the Japan Sea. That is why the sea level rise in the end of September was observed in wide areas. The SSH signals associated with the CTW are decomposed into the steric and non-steric components. The steric SSH signals propagate along the continental slope south of Japan, while the non-steric signals are confined in coastal areas typically shallower than $200 \mathrm{~m}$.

In addition, we conduct a modal characteristic analysis to further investigate the characteristics of the CTW. Comparison of calculated modal structures along a zonal section southeast of Kyushu with vertical structures for alongshore velocity and density anomalies associated with the CTW suggests that the first mode characterized by a baroclinic Kelvin wave is the most dominant and that there are also some contributions from higher modes. In fact, the phase speed for the first mode is calculated at $2.96 \mathrm{~m} \mathrm{~s}^{-1}$, which compares well with a tide gauge-based estimate.

It is worth emphasizing that the two mechanisms for the 2011 UHSL shown in Fig. 13 are both related to variations of the Kuroshio path south of Japan. Although it is well known that the Kuroshio path has a large impact on sea level variability along the Japanese coast, the specific mechanism has not been adequately studied yet. The mechanisms proposed in this study would be thus important not only for this event focused on in this study, but also for understanding the impact of the Kuroshio on the coastal sea level. In particular, the CTW induced by the Kuroshio path, which can change sea level over wide areas of the Japanese coast, might be a key process for the sea level variability along the Japanese coast. It should be clarified in future study.

Acknowledgements We are grateful to the two anonymous reviewers for their constructive comments that helped to improve the early version of the manuscript. This work was funded by the Meteorological Research Institute, and was also partly supported by JSPS KAKENHI Grant Numbers JP19K03978, JP16H02226, JP19H05701, and by JST CREST Grant Number JPMJCR19F1.

Open Access This article is licensed under a Creative Commons Attribution 4.0 International License, which permits use, sharing, adaptation, distribution and reproduction in any medium or format, as long as you give appropriate credit to the original author(s) and the source, provide a link to the Creative Commons licence, and indicate if changes were made. The images or other third party material in this article are included in the article's Creative Commons licence, unless indicated otherwise in a credit line to the material. If material is not included in the article's Creative Commons licence and your intended use is not permitted by statutory regulation or exceeds the permitted use, you will need to obtain permission directly from the copyright holder. To view a copy of this licence, visit http://creativecommons.org/licenses/by/4.0/.

\section{Appendix A: Steric and non-steric components of SSH}

Vertical integration of the hydrostatic balance from the bottom to the surface yields

$\int_{-H}^{\eta} d z=-\int_{p_{b}}^{p_{s}} \frac{1}{\rho g} d p$

where $\eta$ is the sea level, $H$ is the bottom depth, $\rho$ is the seawater density, $g$ is the gravity accerelation, and $p_{s}$ and $p_{b}$ are the pressure at the sea surace and bottom. If the surface and bottom pressure are decomposed into a temporal mean $(\bar{p})$ and a deviation from it $\left(p^{\prime}\right),($ A.1) becomes

$$
\begin{aligned}
\eta+H= & \int_{\overline{p_{s}}+p_{s}^{\prime}}^{\overline{p_{s}}} \frac{1}{\rho g} d p+\int_{\overline{p_{s}}}^{\overline{p_{b}}} \frac{1}{\rho g} d p+\int_{\overline{p_{b}}}^{\overline{p_{b}}+p_{b}^{\prime}} \frac{1}{\rho g} d p \\
& \sim \underbrace{-\frac{p_{s}^{\prime}}{\rho_{s} g}}_{\mathrm{IB}}+\underbrace{\int_{\overline{p_{s}}}^{\overline{p_{b}}} \frac{1}{\rho g} d p}_{\text {steric }}+\underbrace{\frac{p_{b}^{\prime}}{\rho_{b} g}}_{\text {non-steric }} .
\end{aligned}
$$

Here, we assume the surface density $\rho_{s}$ and bottom density $\rho_{b}$ to be constant. The first term on the right hand side of (A.2) represents an inverted barometer (IB) response to atmospheric pressure, which is zero in this study because the ocean model used does not include this effect. The second term indicates the steric comonent, which is related to density variations in the ocean interior. The third term is the non-steric component, which arises from variations in bottom pressure.

For computation, the steric component is calculated by

(steric) $=-\frac{1}{\rho_{0}} \int_{-H}^{0} \Delta \rho(T, S, z) d z$,

where $\rho_{0}$ is a reference density, $H$ the bottom depth, and $\Delta \rho(T, S, z)$ the density anomaly from the reference state ( $T=0{ }^{\circ} \mathrm{C}$ and $S=35 \mathrm{psu}$ ). The bottom pressure anomaly $p_{b}^{\prime}$ in the non-steric term is calculated as the deviation from the temporal mean of the bottom pressure $p_{b}$, which is represented by

$p_{b}=g \int_{-H}^{\eta} \rho(T, S, z) d z$.

We have confirmed that the sum of the steric and non-steric components diagnosed by (A.3) and (A.4) explains more than $99 \%$ of model SSH variations in a free simulation experiment. 


\section{Appendix B: Calculation of modal characteristics for CTWs}

In this appendix, an outline of the modal characteristic analysis for CTWs is described according to Brink (1982), Brink and Chapman (1987), and Igeta et al. (2007). We consider a linearlized, hydrostatic, Boussinesq, inviscid ocean on a $f$-plane, where the stratification is horizontally uniform and the bottom topography varies only in the direction normal to the coastline. Taking the $x$-axis to be the direction normal to the coastline (positive offshore), the $y$-axis along the coastline, and the $z$-axis directed upward, the equations of motion are

$-f v=-\frac{1}{\rho_{0}} \frac{\partial p}{\partial x}$

$\frac{\partial v}{\partial t}+f u=-\frac{1}{\rho_{0}} \frac{\partial p}{\partial y}$

$\rho^{\prime} g=-\frac{\partial p}{\partial z}$

$\frac{\partial u}{\partial x}+\frac{\partial v}{\partial y}+\frac{\partial w}{\partial z}=0$

$\frac{\partial \rho^{\prime}}{\partial t}+w \frac{\partial \bar{\rho}}{\partial z}=0$,

where $u, v$ and $w$ are offshore, alongshore, and vertical velocity components, $p$ is the purturbation pressure, $f$ is the Coriolis parameter, and $g$ is the accerelation due to gravity. The density is written by

$\rho(x, y, z, t)=\rho_{0}+\bar{\rho}(z)+\rho^{\prime}(x, y, z, t)$,

where $\rho_{0}$ is a constant vlue, and $\bar{\rho}(z)$ and $\rho^{\prime}(x, y, z, t)$ are a depth-dependent reference field and a deviation from it, respectively. Equations (A.5)-(A.9) reduce to

$\frac{\partial^{3} p}{\partial x^{2} \partial t}+f^{2} \frac{\partial}{\partial z}\left(\frac{1}{N^{2}} \frac{\partial^{2} p}{\partial z \partial t}\right)=0$,

where $N$ is the Brunt-Väisärä frequency defined by

$N^{2} \equiv-\frac{g}{\rho_{0}} \frac{\partial \bar{\rho}}{\partial z}$.

The boundary conditions are set as follows:

$g \frac{\partial p}{\partial z}+N^{2} p=0 \quad$ at $\quad z=0$, $f \frac{\partial p}{\partial y}+\frac{\partial^{2} p}{\partial x \partial t}=0 \quad$ at $\quad x=0$

$f^{2} \frac{\partial^{2} p}{\partial z \partial t}+N^{2}\left(f \frac{\partial p}{\partial y}+\frac{\partial^{2} p}{\partial x \partial t}\right) \frac{\partial h}{\partial x}=0 \quad$ at $\quad z=-h(x)$,

$p \rightarrow 0 \quad$ at $\quad x \rightarrow \infty$,

where $h(x)$ is the local depth. To find the free coastal trapped waves, we seek solutions of the form

$p=\sum_{n} F_{n}(x, z) \exp \left[i\left(l_{n} y+\omega_{n} t\right)\right]$,

where $l_{n}, \omega_{n}$ and $F_{n}(x, z)$ are the wavenumber, frequency and offshore-vertical modal structure for the $n$-th mode. Substituting (A.17) into (A.11), we get

$\frac{\partial^{2} F_{n}}{\partial x^{2}}+f^{2} \frac{\partial}{\partial z}\left(\frac{1}{N^{2}} \frac{\partial F_{n}}{\partial z}\right)=0$.

Equation (A.18) and boundary conditions for $F_{n}(x, z)$, which can be obtained by substitution of (A.17) into (A.13)-(A.16), give a two-dimensional eigenvalue problem.

For computation, the vertical profile of the Brunt-Väisärä frequency is calculated by using 5-day (26-30 September 2011) mean density along the zonal section at $31.5^{\circ} \mathrm{N}$ southeast of Kyushu (see Fig. 1b) in the XCTW experiment as the reference density $\bar{\rho}(z)$. To solve the eigenvalue problem, we utilized the program of Brink and Chapman (1987).

\section{References}

Bloom SC, Takacs LL, Silva AMD, Ledvina D (1996) Data assimilation using incremental analysis updates. Mon Wea Rev 124:1256-1271

Brink KH (1982) A comparison of long coastal trapped wave theory with observations off peru. J Phys Oceanogr 12:897-913

Brink KH, Chapman DC (1987) Programs for computing properties of coastal-trapped waves and wind-driven motions over the continental shelf and slope. WHOI Tech. Rep. 2nd ed., Woodshole Oceanographic Institution, Woods Hole

Igeta Y, Kitade Y, Matsuyama M (2007) Characteristics of coastaltrapped waves induced by typhoon along the southeast coast of honshu, japan. J Oceanogr 63:745-760

Igeta Y, Yamazaki K, Watanabe T (2015) Amplification of coastaltrapped waves resonantly generated by wind around sado island, japan. J Oceanogr 71:41-51

Isozaki I (1972) Unusually high mean sea level in september 1971 along the south coast of japan -1. Some aspects of high sea level with time scale more than one week-. Pap Meteorol and Geophys $23: 243-257$

Kajiura K (1974) Effect of stratification on long period trapped waves on the shelf. J Oceanogr Soc Japan 30:271-281 
Kawabe M (1980) Sea level variations along the south coast of japan and the large meander in the kuroshio. J Oceanogr Soc Japan 36:97-104

Kida S, Qiu B, Yang J, Lin X (2016) The annual cycle of the japan sea throughflow. J Phys Oceanogr 46:23-39

Kitade Y, Matsuyama M (2000) Coastal-trapped waves with severalday period caused by wind along the southeast coast of honsyu, japan. J Oceanogr 56:727-744

Kubota M (1981) Continental shelf waves off the fukushima coast part i: observations. J Oceanogr Soc Japan 37:267-278

Kubota M (1985) Continental shelf waves off the fukushima coast part 3: numerical experiments. J Oceanogr Soc Japan 41:105-112

Kurashige K (1972) Unusually high mean sea level in september 1971 along the south coast of japan-2. Unusual high or low sea level in tokyo bay- statistical analysis. Pap Meteorol and Geophys 23:259-276

Miyama T, Miyazawa Y (2014) Short-term fluctuations south of japan and their relationship with the kuroshio path: 8- to 36-day fluctuations. Ocean Dyn 64:537-555

Miyazaki M (1972) Unusually high mean sea level in september 1971 along the south coast of japan - an introductory note-. Pap Meteorol and Geophys 23:241-242

Ohshima KI (1994) The flow system in the japan sea caused by a sea level difference through shallow straits. J Geophys Res 99:9925-9940

Sakamoto K, Yamanaka G, Tsujino H, Nakano H, Urakawa S, Usui N, Hirabara M, Ogawa K (2016) Development of an operational coastal model of the seto inland sea, japan. Ocean Dyn 66:77-97

Senjyu T, Matsuyama M, Matsubara N (1999) Interannual and decadal sea-level variations along the japanese coast. J Oceanogr 55:619-633
Takagi H, Kidu S, Shibayama T (2008) Analysis of abnormal tides in tokyo bay induced by incoming continental-shelf waves. Proc Coast Eng 55:1306-1310 (in Japanese with English abstract)

Tsujino H, Usui N, Nakano H (2006) Dynamics of kuroshio path variations in a high-resolution gcm. J Geophys Res 111:C11001. https ://doi.org/10.1029/2005JC0031180

Tsujino H, Nakano H, Motoi T (2008) Mechanism of currents through the straits of the japan sea: mean state and seasonal variation. $\mathrm{J}$ Oceanogr 64:141-161

Tsujino H, Motoi T, Ishikawa I, Hirabara M, Nakano H, Yamanaka G, Yasuda T, Ishizaki H (2010) Reference manual for the meteorological research institute community ocean model (mri.com) version 3. Tech. Rep. 59, Meteorol. Res. Inst., Tsukuba

Umeki Y (2003) On the state of occurrence and estimation for factors of occurrence of extra-high tide events recently observed in western japan. Coastal Development Institute of Technology 3:(in Japanese with English abstract)

Usui N, Ishizaki S, Fujii Y, Tsujino H, Yasuda T, Kamachi M (2006) Meteorological research institute multivariate ocean variational estimation (move) system: Some early results. Adv Space Res 37:806-822

Usui N, Fujii Y, Sakamoto K, Kamachi M (2015) Development of a four-dimensional variational assimilation system for coastal data assimilation around japan. Mon Wea Rev 143:3874-3892

Woodworth PL, Melet A, Marcos M, Ray RD, Wöppelmann G, Sasaki Y, Cirano M, Hibbert A, Huthnance JM, Monserrat S, Merrifield MA (2019) Forcing factors affecting sea level changes at the coast. Surv Geophys 40:1351-1397

Zhang Z, Ichikawa K (2005) Influence of the kuroshio fluctuations on sea level variations along the south coast of japan. J Oceanogr 61:979-985 